\title{
Anthropometrical Characteristics of Subjects in Predicting Technique Achievements of Basic Turn in Alpine Skiing
}

\author{
Características Antropométricas de Sujetos en la Predicción de \\ Técnicas de Rendimiento en el Giro Básico del Esquí Alpino
}

Rasid Hadzic",*; Dusko Bjelica*; Georgi Georgiev"**; Dobrislav Vujovic* \& Stevo Popovic*

HADZIC, R.; BJELICA, D.; GEORGIEV, G.; VUJOVIC, D. \& POPOVIC, S. Anthropometrical characteristics of subjects in predicting technique achievements of basic turn in alpine skiing. Int. J. Morphol., 32(1):232-240, 2014.

SUMMARY: This research analyzes the techniques involved in basic turn in relation to anthropometric characteristics of subjects. The aim of this study was to determine the difference in the technique of basic turn performance in relation to anthropometric characteristics of subjects. In a sample of 30 students, average age 22 years, male, measuring by 12 anthropometric measures and a situational-motor test was carried out. Alpine skiing technique was assessed through primary windings, the technical element of skiing which is present in the basic form of skiing. Based on these results, we can conclude that, the differences are established and boundaries are clearly defined in the level of adoption of the basic turn techniques between subsamples in relation to anthropometric characteristics.

KEY WORDS: Alpine skiing; Basic turn; Anthropometric characteristics.

INTRODUCTION

Development and improvement of ski equipment, ski primarily, entailed the emergence and production of the first carving skis that allow development of new, carving skiing technique (Hirano \& Tada, 2005; Hörterer, 2005). Alpine skiing is the specific and complex sport activity that takes place on a different configuration of the terrain and that requires the skiers to have skiing technique of high quality that can be applied in given circumstances (Hadzic et al., 2012).

Carving skiing technique enables all the time driving on the curb turn and turn without skidding performance (Hörterer). Also, the appearance of carving ski caused an innovation in the learning process of carving ski technique.

In the process of learning of ski technique as a transitional phase between the elements of the plow and parallel ski technique often used today is the so-called wedge $(\mathrm{V})$ position of skis, in which the last parts of the skis are less widespread compared to the pulmonary position (Lesnik et al., 2002). Using the ski V-position in the learning process, either as a methodological exercise or as an element of ski technique, allows gradual buildup to the turnaround performance in its entirety by the parallel ski technique (Cigovski et al., 2010). This learning approach completely omits elements of the plow ski technique (Murovec, 2006).

Therefore, it is important to identify factors that play a significant role in the adoption of skiing technique, and that each skier, beginner, through the alpine ski schools adopt the elements of alpine skiing at a high level (Joksimovic et al., 2009).

It can be said that the success in alpine skiing depends primarily on the level of the adopted specific motor skills (Kuna et al., 2008).

The basic turn is an element of the skiing techniques that combine wedge turns and parallel skiing technique (Hadzic, 2008). It is because of the new approach for learning alpine skiing; the goal of this work is to determine the difference in the technique of basic turn perfor-

\footnotetext{
" Faculty for Sport and Physical Education, University of Montenegro, Niksic, Montenegro.

** Faculty of Physical Education, University of Ss. Cyril and Methodius, Skopje, Macedonia.
} 
mance in relation to the anthropometric characteristics of the subjects, and to determine which anthropometric characteristics are contributing to the adoption of the basic turn techniques for ski beginners.

\section{MATERIAL AND METHOD}

The key issue, and the whole problem orientation of this research is related to the analysis of the performance of basic turn in alpine skiing in relation to anthropometric characteristics of subjects.

Measurement of anthropometric characteristics was carried out at the Faculty of Sports and Physical Education, before departure of students in compulsory practical teaching of skiing. Assessment of skiing technique was performed on the slopes of Kopaonik realized after a seven-day program. Ski teaching lasted for seven days, a total of 42 hours, and was performed by three teachers at the identical program. During the day the class is created with the total of 6 hours where the first three hours was applied learning elements of ski technique and the threehour afternoon were for training purposes.

Assessors were teachers who have vast experience in this business. Each subject was evaluated by all three assessors from different positions. Three independent assessors gave the ratings to each respondent for the demonstration of selected elements of ski technique - basic turn as the final score takes the average of the three ratings. Evaluation of adoption levels of skiing skills in participants valued the score of 5 to 10 relating to the conduct of skis arc turns, speed control based on completion of shift, the appropriate attitude that ensures the center of gravity in the middle of the foot, the adequacy and continuity of vertical movement matched with his wand, dynamics, rhythm and harmony of character performance, ease and softness of demonstration.

During processing of the data, based on the final (formed) grades in the performance evaluation of basic meandering, sample is divided into three sub-samples, which were called "poor", "moderate" and "good". The first sub-sample ("bad") included the subjects who received grades 5 and 6 to the techniques of basic turn, the second ("moderate") included the subjects who received grades 7 and 8 of the techniques of basic turn and third sub-sample ("good") included the subjects who received grades 9 and 10 for the performed technique of basic turn.

Subject's Sample. In this study, the sample entered the
30 students of the Faculty of Sports and Physical Education, ski novice male, average age 22 years, divided into three sub-samples compared to the techniques involved in basic turn as follows: first sub-sample consists of 14 subjects classified as ("weak"), the second of 9 respondents classified as ("moderate") and the third subsample consists of 7 respondents classified as ("good").

A Sample of Measuring Instruments. Anthropometric characteristics followed in this study were measured according to the instructions and regulations of the International Biological Program (IBP). The program consists of 39 measures (Misigoj-Durakovic, 2008), some of which were used in this study as follows: body weight, chest circumference, thigh circumference, body height, lower leg length, arm length, upper arm skinfold, abdominal skinfold, back skinfold, knee diameter, pelvic width, shoulder width. Criterion variable in this study was the basic turn.

Methods of data processing. In line with the aim of research appropriate statistical methods of data was chosen. The first part shows the central and dispersion parameters, measures of asymmetry and kurtosis compared to the monitored parameters. The second part analyzes the differences between respondents in the technique of basic turn in relation to anthropometric characteristics. Then the characteristics and homogeneity of each sub-sample are defined in relation to the basic techniques of performing turn and the distance between them is determined. Finally, the results are presented graphically.

To avoid losing information, finding the finest links and information on nonparametric sizes, data scaling was performed on contingency tables. Based on the above it is evident that the application of discriminant analysis (DISCKRA) on the scaled data is possible.

By calculating the coefficient of discrimination features that determine the specificity and characteristics of the subsamples are standing out to be excluded from further processing, ie. reduction of the observed space is applied. In addition, the representation of the homogeneity of the subsamples, the distance between them and cluster analysis, is aimed to study observed phenomena as best as possible.

The purpose of the application of mathematical and statistical analysis aims to determine the characteristics of each sub-sample, the homogeneity and the distance between them in relation to the derived characteristics that could be used for reliably and accurately forecasting and prediction with a specified reliability. 


\section{RESULTS AND DISCUSSION}

The basic parameters of the anthropometric characteristics of the respondents in relation to the basic turn technique performance. In accordance with the defined purpose of research, the thematic unit anthropometric characteristics of the respondents will be analyzed in relation to the techniques involved in basic turn in alpine skiing. The central and dispersion parameters, measures of asymmetry and kurtosis of the mentioned anthropometric characteristics represent the basic technique of turn and direct us to the possibility of using parametric procedures.

Minimum (min) and maximum $(\max )$ values of the anthropometric characteristics of subgroups "weak" indicates that the values are in the expected range (Table I). Greater heterogeneity of the coefficient of variation (CV) indicates the subsample "weak" by the following characteristics: forearm skin fold (AKNNL) (48.92), abdominal skinfold (AKNTR) (58.01), skinfold (AKNL) (64.43). The coefficient of variation $(\mathrm{CV})$ indicates the homogeneity characteristics: length of the lower leg (ADUPK) (23.97), body weight (AMAST) (19.02), chest circumference (AOGK) (8.61), the volume of the thigh (AONDK) (9.83), body height (Avista) (4.12), arm length (Adruk) (4.81), knee diameter (ADKL) (11.35), pelvic width (Asik) (6.14), shoulder width (ASIR) (6.55).

Increased values of Skewness (Sk) indicate that the distribution is highly negative asymmetric with the following characteristics: body mass (AMAST) (1.28), chest circumference (AOGK) (1.20), abdominal skinfold (AKNTR) (0.94), skinfold (AKNL) (2.49). This means that the distribution of the curve tends towards higher values, or that there are more larger values compared to the normal distribution.

Increased values of Skewness (Sk) indicate that the distribution is very positively asymmetrical with the feature of shoulder width (ASIRA) (-1.41). This means that the results of the distribution curve tends to lower values and have smaller values compared to the normal distribution.

Normal (tolerant) asymmetry values of Skewness (Sk) are determined by the following characteristics: arm length (ADRUK) (-0.03), pelvic width (ASIKA) (0.02), the volume of the thigh (AONDK) (0.14), body height (AVIST) (0.22), length of the lower leg (ADUPK) (0.54), forearm skin fold (AKNNL) (0.69) knee diameter (ADKL) (-0.73).

Higher values of Kurtosis $(\mathrm{Ku})$ indicate the elongated curve, with the following characteristics: body mass (AMAST) (0.74), chest circumference (AOGK) (0.50), skinfold (AKNL) (5.65), shoulder width (ASIRA) (2.21). Negative values of Kurtosis $(\mathrm{Ku})$ indicates the flattened curve, with the following characteristics: volume of the thigh (AONDK) (-0.46), body height (AVIST) $(-0.87)$, the length of the lower leg (ADUPK) (-1.60), arm length (ADRUK) ($1.15)$, forearm skin fold (AKNNL) (-0.79), abdominal skinfold (AKNTR) (-0.27), knee diameter (ADKL) (-0.56), pelvic width (AASIKA) (-1.23).

Minimum (min) and maximum (max) values of the anthropometric characteristics of subgroups "moderate" indicates that the values are in the expected range (Table II). Greater heterogeneity of the coefficient of variation (CV) indicates the subsample "moderate" by the following

Table I. The central and dispersion parameters and measures of skewness and kurtosis of the anthropometric characteristics of the sub-sample - "weak" (14).

\begin{tabular}{lccccccccc}
\hline & M & SD & Min & Max & CV & \multicolumn{2}{c}{ Range } & Sk & Ku \\
\hline AMAST & 78.50 & 14.93 & 61.0 & 114.0 & 19.02 & 69.88 & 87.12 & 1.28 & 0.74 \\
AOGK & 97.00 & 8.35 & 88.0 & 117.0 & 8.61 & 92.18 & 101.82 & 1.20 & 0.50 \\
AONDK & 53.64 & 5.27 & 44.0 & 64.0 & 9.83 & 50.60 & 56.69 & 0.14 & -0.46 \\
AVIST & 178.00 & 7.34 & 167.0 & 191.0 & 4.12 & 173.76 & 182.24 & 0.22 & -0.87 \\
ADUPK & 54.64 & 9.10 & 51.0 & 59.0 & 16.65 & 57.54 & 76.03 & 0.54 & -1.60 \\
ADRUK & 76.86 & 3.70 & 71.0 & 83.0 & 4.81 & 74.72 & 78.99 & -0.03 & -1.15 \\
AKNNL & 10.90 & 5.33 & 5.0 & 22.0 & 48.92 & 7.82 & 13.98 & 0.69 & -0.79 \\
AKNTR & 17.05 & 9.89 & 6.0 & 39.0 & 58.01 & 11.34 & 22.76 & 0.94 & -0.27 \\
AKNL & 13.42 & 8.65 & 7.0 & 41.0 & 64.43 & 8.43 & 18.42 & 2.49 & 5.65 \\
ADKL & 9.36 & 1.06 & 7.5 & 10.9 & 11.35 & 8.74 & 9.97 & -0.73 & -0.56 \\
ASIKA & 30.04 & 1.85 & 27.0 & 33.0 & 6.14 & 28.97 & 31.10 & 0.02 & -1.23 \\
ASIRA & 40.86 & 2.68 & 33.5 & 44.0 & 6.55 & 39.31 & 42.40 & -1.41 & 2.21 \\
\hline
\end{tabular}

Legend: M (mean), SD (standard deviation), Min (minimum value), max (maximum value), CV (coefficient of variation), Range (Range), Sk (standardized coefficient of asymmetry, curvature), Ku (standardized coefficient of elongation or flatness). 
Table II. The central and dispersion parameters and measures of asymmetry and kurtosis of the anthropometric characteristics of the sub-sample - "moderate" (9).

\begin{tabular}{lccccccccc}
\hline & M & SD & Min & Max & CV & \multicolumn{2}{c}{ Range } & Sk & Ku \\
\hline AMAST & 79.78 & 12.58 & 65.0 & 104.0 & 15.77 & 70.11 & 89.45 & 0.71 & -0.47 \\
AOGK & 102.78 & 7.74 & 89.0 & 116.0 & 7.53 & 96.82 & 108.73 & -0.06 & -0.20 \\
AONDK & 56.78 & 5.22 & 48.0 & 64.0 & 9.19 & 52.77 & 60.79 & -0.14 & -1.07 \\
AVIST & 179.78 & 6.61 & 172.0 & 190.0 & 3.68 & 174.70 & 184.86 & 0.13 & -1.27 \\
ADUPK & 55.89 & 3.18 & 51.0 & 61.0 & 5.69 & 53.44 & 58.33 & 0.08 & -0.99 \\
ADRUK & 76.67 & 3.67 & 71.0 & 82.0 & 4.79 & 73.84 & 79.49 & -0.26 & -1.05 \\
AKNNL & 10.57 & 3.11 & 5.6 & 17.0 & 29.41 & 8.18 & 12.96 & 0.60 & 0.55 \\
AKNTR & 21.84 & 6.86 & 13.0 & 35.0 & 31.39 & 16.57 & 27.12 & 0.76 & -0.33 \\
AKNL & 14.92 & 5.22 & 8.0 & 25.0 & 35.00 & 10.91 & 18.94 & 0.45 & -0.32 \\
ADKL & 9.91 & 1.05 & 8.0 & 11.4 & 10.57 & 9.10 & 10.72 & -0.34 & -0.60 \\
ASIKA & 29.78 & 1.42 & 27.5 & 32.0 & 4.76 & 28.69 & 30.87 & -0.22 & -0.76 \\
ASIRA & 41.56 & 2.76 & 36.0 & 46.0 & 6.63 & 39.44 & 43.67 & -0.46 & 0.38 \\
\hline
\end{tabular}

Legend: M (mean), SD (standard deviation), Min (minimum value), max (maximum value), CV (coefficient of variation), Range (Range), Sk (standardized coefficient of asymmetry, curvature), Ku (standardized coefficient of elongation or flatness).

characteristics: forearm skin fold (AKNNL) (29.41), abdominal skinfold (AKNTR) (31.39), skinfold (AKNL) (35.00). The coefficient of variation (CV) indicates the homogeneity characteristics: body mass (AMAST) (29.41), chest circumference (AOGK) (7.53), thigh circumference (AONDK) (9.19), body height (AVIST) (3.68), length of the lower leg (ADUPK) (5.69), arm length (ADRUK) (4.79), knee diameter (ADKL) (10.57), pelvic width (ASIKA) (4.76) and shoulder width (ASIRA) (6.63). Increased values of Skewness (Sk) indicating that the distribution is highly negatively or positively asymmetric are not notified.

Normal (tolerant) asymmetry values of Skewness (Sk) are determined by the following characteristics: body mass (AMAST) (0.71), body height (AVISTA) (0.13), length of the lower leg (ADUPK) (0.08), forearm skin fold (AKNNL) (0.60), abdominal skinfold (AKNTR) (0.76), skinfold (AKNL) (0.45), chest circumference (AOGK) ($0.06)$, the volume of the thigh (AONDK) $(-0.14)$, arm length (ADRUK) (-0.26), knee diameter (ADKL) (-0.34), pelvic width (ASIK) (-0.22), shoulder width (ASIR) (-0.46).

Higher values of Kurtosis $(\mathrm{Ku})$ indicate the elongated curve, with the following characteristics: forearm skin fold (AKNNL) (0.55), shoulder width (ASIR) (0.38). Negative values of Kurtosis $(\mathrm{Ku})$ indicates the flattened curve, with the following characteristics: body weight (AMAST) (-0.47), chest circumference (AOGK) (-0.20), the volume of the thigh (AONDK) (-1.07), body height (AVISTA) (-1.27), length of the lower leg (ADUPK) (-0.99), arm length (ADRUK) (1.05), abdominal skinfold (AKNTR) (-0.33), skinfold (AKNL) (-0.32), knee diameter (ADKL) $(-0.60)$, pelvic width (ASIK) (-0.76).
Minimum (min) and maximum (max) values of the anthropometric characteristics of subgroups "good" indicates that the values are in the expected range (Table III). Greater heterogeneity of the coefficient of variation (CV) indicates the subsample "good" by the following characteristics: forearm skin fold (AKNNL) (38.36), abdominal skinfold (AKNTR) (38.94), skinfold (AKNL) (20.94). The coefficient of variation $(\mathrm{CV})$ indicates the homogeneity characteristics: body mass (AMAST) (9.89), chest circumference (AOGK) (16.90), the volume of the thigh (AONDK) (4.39), body height (AVIST) (3.00), the length of the lower leg (ADUPK) (4.20), arm length (ADRUK) (4.88), knee diameter (ADKL) (7.90), pelvic width (ASIKA) (5.54), shoulder width (ASIRA) (8.96).

Increased values of Skewness (Sk) indicate that the distribution is highly negatively asymmetric at shoulder width (ASIRA) (1.09). Increased values of Skewness (Sk) indicates extremely positive asymmetric distribution with the Middle chest circumference (AOGK) (-1.31).

Normal (tolerant) asymmetry values of Skewness (Sk) are determined by the following characteristics: forearm skin fold (AKNNL) (0.75), abdominal skinfold (AKNTR) (0.68), skinfold (AKNL) (0.49), knee diameter (ADKL) (0.52), the volume of the thigh (AONDK) (0.02), body weight (AMAST) (-0.55), body height (AVIST) $(-0.07)$, the length of the lower leg (ADUPK) (-0.07), arm length (ADRUK) (-0.28), pelvic width (ASIK) (-0.47).

Higher values of Kurtosis $(\mathrm{Ku})$ indicate the elongated curve, with the following characteristics: average thorax (AOGK) (0.77), pelvic width (ASIKA) (0.29), shoulder 
Table III. The central and dispersion parameters and measures of asymmetry and kurtosis of the anthropometric characteristics of the sub-sample - "good" (7)

\begin{tabular}{lcccccccccc}
\hline & M & SD & Min & Max & CV & \multicolumn{2}{c}{ Range } & Sk & Ku & p \\
\hline AMAST & 76.29 & 7.54 & 66.0 & 84.0 & 9.89 & 69.31 & 83.26 & -0.55 & -1.29 & 0.944 \\
AOGK & 93.57 & 15.81 & 61.0 & 110.0 & 16.90 & 78.95 & 108.20 & -1.31 & 0.77 & 0.996 \\
AONDK & 55.57 & 2.44 & 52.0 & 59.0 & 4.39 & 53.31 & 57.83 & 0.02 & -1.09 & 0.988 \\
A VIST & 179.57 & 5.38 & 172.0 & 187.0 & 3.00 & 174.59 & 184.55 & -0.07 & -1.29 & 0.983 \\
ADUPK & 56.43 & 2.37 & 53.0 & 60.0 & 4.20 & 54.24 & 58.62 & -0.07 & -0.89 & 1.000 \\
ADRUK & 77.29 & 3.77 & 72.0 & 82.0 & 4.88 & 73.79 & 80.78 & -0.28 & -1.35 & 0.995 \\
AKNNL & 12.44 & 4.77 & 7.0 & 21.0 & 38.36 & 8.03 & 16.86 & 0.75 & -0.54 & 0.855 \\
AKNTR & 15.69 & 6.11 & 9.0 & 26.2 & 38.94 & 10.03 & 21.34 & 0.68 & -0.82 & 0.810 \\
AKNL & 12.11 & 2.54 & 9.0 & 16.4 & 20.94 & 9.77 & 14.46 & 0.49 & -0.81 & 0.911 \\
ADKL & 10.21 & 0.81 & 9.3 & 11.6 & 7.90 & 9.47 & 10.96 & 0.52 & -0.73 & 0.982 \\
ASIKA & 29.50 & 1.63 & 26.5 & 32.0 & 5.54 & 27.99 & 31.01 & -0.47 & 0.29 & 0.570 \\
ASIRA & 40.86 & 3.66 & 37.0 & 48.0 & 8.96 & 37.47 & 44.24 & 1.09 & 0.13 & 0.642 \\
\hline
\end{tabular}

Legend: M (mean), SD (standard deviation), Min (minimum value), max (maximum value), CV (coefficient of variation), Range (Range), Sk (standardized coefficient of asymmetry, curvature), Ku (standardized coefficient of elongation or flatness).

width (ASIR) (0.13). Negative values of Kurtosis $(\mathrm{Ku})$ indicates the flattened curve, with the following characteristics: body mass (AMAST) (-1.29), the volume ofthe thigh (AONDK) (-1.09), body height (AVISTA) ($1.29)$, length of the lower leg (ADUPK) (-0.89), length of hand (ADRUK) (-1.35), forearm skin fold (AKNNL) (-0.54), abdominal skinfold (AKNTR) (-0.82), skinfold (AKNL) ($0.81)$, knee diameter (ADKL) (-0.73).

Analysis of the difference in the technique of basic turn in relation to anthropometric characteristics of subjects. This subsection will prove or reject the claim that there is a significant difference in the technique of basic turn in relation to anthropometric characteristics of subjects.

The results of discriminant analysis (DISKRA) to determine the significance of differences in the technique of basic turn in relation to anthropometric characteristics of subjects $(n=12)$, it clearly shows, based on the value of $p$ $=0.000(\mathrm{~F}=32.408)$, that there is a difference and clearly defined boundary in the technique of basic turn between respondents which is manifested latently.

A review of Table IV, when considering the anthropometric characteristics of the subjects individually using discriminant analysis (DISKRA), is giving us discrimination coefficient (kdsk) that indicates to the claim that there is a difference in the technique of basic turn between respondents and that the greatest contribution to discrimination, that is the biggest difference, is with the following variables: body mass (0.662), abdominal skinfold (0.584), the volume of the thigh $(0.581)$, forearm skin fold (0.527), pelvic width (0.447), body height $(0.366)$, lower leg length (0.218), knee diameter (0.176), shoulder width
(0.117), skinfold (0.110), arm length (0.064), chest circumference $(0.022)$.

Characteristics and homogeneity of the subsamples in the technique of basic turn in relation to anthropometric characteristics. Based on the previous discussion and analysis of samples from 30 subjects, in accordance with the methodology applied, the logical sequence of study was to determine the characteristics and homogeneity of each subsample based on the performance technique of basic turn and distance between them.

The fact that $p=0.000$ of discriminant analysis (DISKARA) means that there are clearly defined boundaries between subsamples on the basis of a technique of basic turn, so it is possible to determine the feature of each subsample of the basic turn of a technique in relation to anthropometric characteristics.

The status of each sub-sample performance of the techniques of basic meandering is mostly defined by body mass because the contribution feature characteristics (Table V) are $17.09 \%$ followed by: abdominal skinfold (15.07\%), the volume of the thigh $(15.00 \%)$, upper arm skin fold $(13.60 \%)$, pelvic width $(11.54 \%)$, body height $(9.45 \%)$, lower leg length $(5.63 \%)$, knee diameter (4.54\%), shoulder width (3.02\%), skinfold (2.84\%), arm length (1.65\%) and chest circumference $(0.57 \%)$. Homogeneity of the subsamples 'weak' is $92.86 \%$, for subsample of "moderate" are $66.67 \%$, and for sub-samples "good" is $85.71 \%$.

Based on the above it can be said that the characteristics of the subsample of "weak" features has 13 of 14 subjects, which means that one subject have other 
Table IV The significance of differences in the technique of basic turn in relation to anthropometric characteristics of subjects.

\begin{tabular}{lcc}
\hline & F & k.dsk \\
\hline AMAST & 0.145 & 0.662 \\
AOGK & 1.668 & 0.022 \\
AONDK & 1.241 & 0.581 \\
AVIST & 0.237 & 0.366 \\
ADUPK & 3.330 & 0.218 \\
ADRUK & 0.057 & 0.064 \\
AKNNL & 0.362 & 0.527 \\
AKNTR & 1.315 & 0.584 \\
AKNL & 0.347 & 0.110 \\
ADKL & 1.915 & 0.176 \\
ASIKA & 0.244 & 0.447 \\
ASIRA & 0.177 & 0.117 \\
\hline
\end{tabular}

Legend: k.dsk is the coefficient of discrimination.

This means that one can expect that subjects whose characteristics are similar to that of sub-sample "weak", but they belonging based on basic turn technique is unknown, have reliability of $92.9 \%$ of belonging just to the subsample of "weak", ie., it is possible to forecast with certainty that a particular respondent with such features can be classified in the sub-sample "weak".

Based on the anthropometric characteristics of the respondents, it can be said that the sub-samples have the following properties:

- Subsample of the "weak" have less pronounced following characteristics: body height, diameter and volume of the knee thigh.

- Moderately expressed are following properties: body mass, abdominal skinfold, upper arm skin fold, shoulder width, skinfold, arm length and circumference of the chest.

- More pronounced are following properties: lower leg length and the width of the pelvis.

- Subsample of "moderate" has less pronounced following properties: skin fold, arm, lower leg length and arm length.

- Moderately are expressed the following properties: the width of the pelvis and knee diameter.

Table V. Characteristics and homogeneity of the subsamples based on the performance techniques of basic turn in relation to anthropometric characteristics.

\begin{tabular}{lcccc}
\hline & Slaba & Umerena & Dobara & dpr \% \\
\hline AMAST & umerene & vece & manje & 17.088 \\
AKNTR & umerene & vece*1 & manje & 15.075 \\
AONDK & manje & vece & umerene & 14.997 \\
AKNNL & umerene & manje & vece & 13.604 \\
ASIKA & vece & umerene & manje & 11.538 \\
AVIST & manje & vece & umerene & 9.448 \\
ADUPK & vece*1 & manje & umerene & 5.627 \\
ADKL & manje & umerene & vece*1 & 4.543 \\
A_IRA & umerene & vece & manje & 3.020 \\
AKNL & umerene & vece & manje & 2.839 \\
ADRUK & umerene & manje & vece & 1.652 \\
AOGK & umerene & ve_e & manje & 0.568 \\
n/m & $13 / 14$ & $6 / 9$ & $6 / 7$ & -- \\
\% & 92.86 & 66.67 & 85.71 & -- \\
\hline
\end{tabular}

Legend: hmg - homogeneity; dpr\% - contributing feature characteristics.

Table VI. Distance (Mahalanobis) between the subsamples in the technique of basic turn in relation to anthropometric characteristics of the respondents.

\begin{tabular}{lccc}
\hline & Weak & Moderate & Goods \\
\hline Weak & 0.00 & 2.82 & 2.76 \\
Moderate & 2.82 & 0.00 & 2.54 \\
Goods & 2.76 & 2.54 & 0.00 \\
\hline
\end{tabular}

features rather than the characteristics of their group, homogeneity of subsamples is as great as $92.9 \%$. Characteristics of subgroups 'moderate' has 6 of the 9 subjects, homogeneity is $66.7 \%$ because 3 of the respondents have other features, also features sub-sample "goods" has 6 of the 7 subjects, homogeneity is high at $85.7 \%$ for 1 subject had other characteristics.
- More pronounced are the following properties: body mass, abdominal skinfold, thigh circumference, body height, shoulder width, skinfold and circumference of the chest.

-Subsample of "good" has less pronounced following properties: body mass, abdominal skinfold, pelvic width, shoulder width, skinfold and circumference of the chest.

-Moderately are expressed the following properties: thigh girth, body height and lower leg length.

-More are expressed the following properties: skin fold, arm, knee diameter and length of arms.

By calculating, the Mahalanobis distance between the subsamples in the technique of basic meandering performance it can be obtained another indication of similarity or difference. Distances from Table VI indicate that the least the distance is between subsamples of "good", "moderate" (2.54) and the outermost between sub-samples of "good" and "poor" (2.82).

Based on the displayed dendrogram (Fig. 1) it can be seen that the closest sub-samples are "moderate" and "good" with distance 2.54, and the biggest difference is between the subsamples "weak" and "moderate", distance 2.86 .

Based on the graphic display of ellipses (confidence interval) it may be possible to observe the relative positions and characteristics of each of the three sub-samples ("weak" (1), "moderate" (2) "goods" (3)), on the basis of a technique of basic meandering in relation to the most discriminating 3 


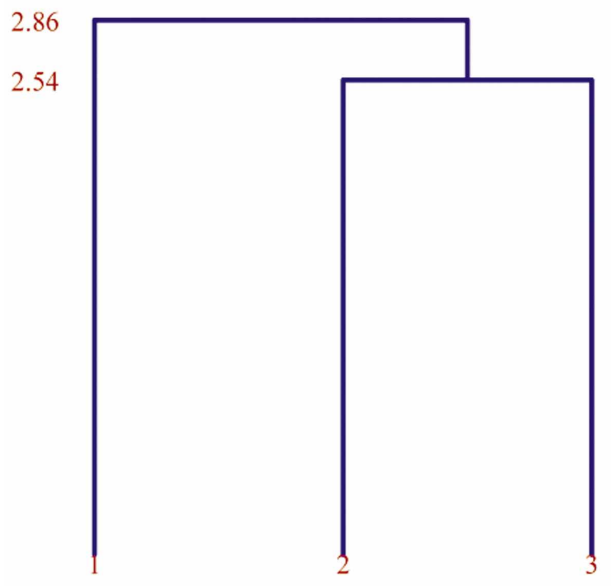

Fig. 1. Graphic differences between the subsamples based on the performance technique of basic turn in relation to the three most discriminating anthropometric characteristics. Legend: weak (poor) (1) moderate (2) good (3).

(features) anthropometric characteristics: body mass (an01), abdominal skinfold (an08), the volume of the thigh (an03) (Fig. 2).

In Figure 2, $\mathrm{X}$-axis (horizontal axis) is the mass of the body (an01) and the ordinate (vertical axis) is the abdominal skinfold (an08). It is noted that in relation to the size of the body, subsample "weak" (1) has the lowest value of anthropometric characteristics, and the highest value is the one of subsample "moderate" (2). In relation to the abdominal skinfold subsample "weak" (1) has the lowest value of anthropometric characteristics, and the highest value has subsample "moderate" (2).

In Figure 3, $\mathrm{x}$-axis (horizontal axis) is the mass of the body (an01) and the ordinate (vertical axis) is the volume of the thigh (an03). It is noted that in relation to the size of the body, subsample "good" (3) has the lowest value of anthropometric characteristics, and the highest value is the one of subsample "moderate" (2). In relation to the volume of the thigh, subsample "weak" (1) has the lowest value of anthropometric characteristics, and the highest value is for the sub-sample "moderate" (2).

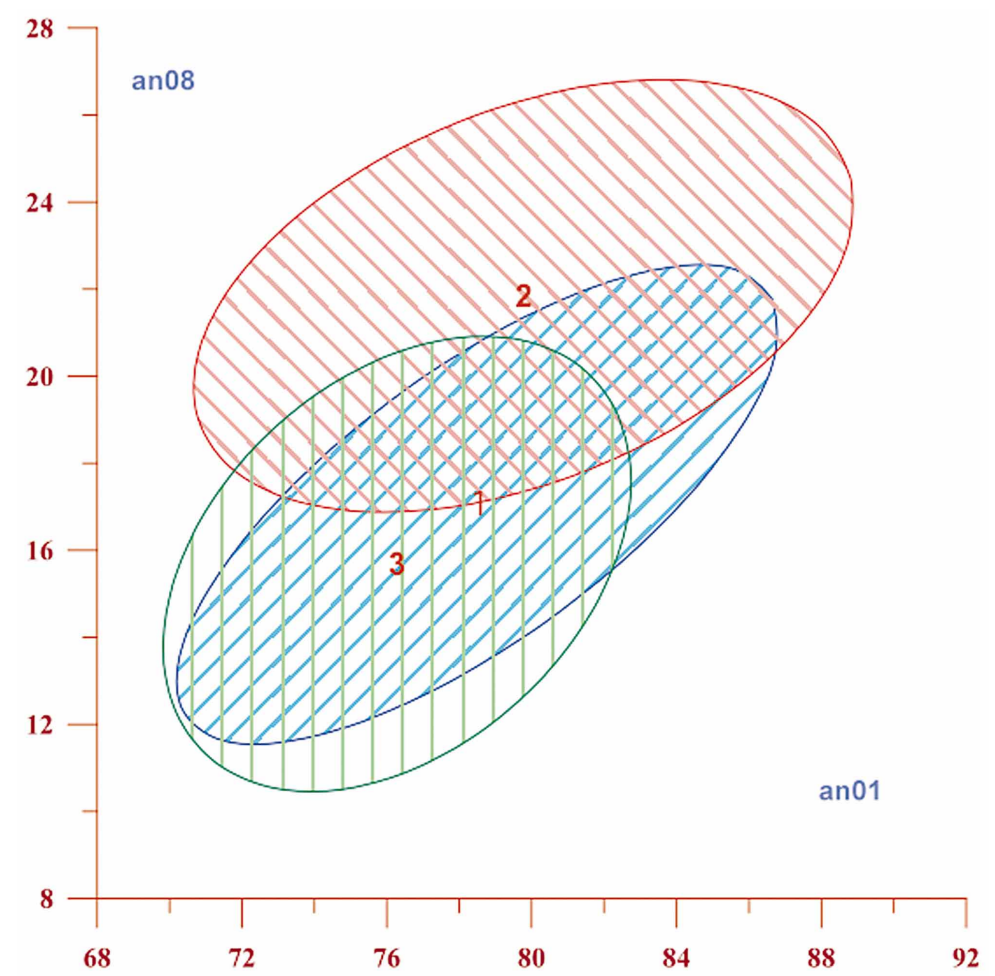

Fig. 2. Ellipses (confidence interval), basic turn of subjects by body mass and abdominal skinfold. Legend: "poor" (weak) (1), "moderate" (2) "goods" (3), body height (an04), abdominal skinfold (an08).

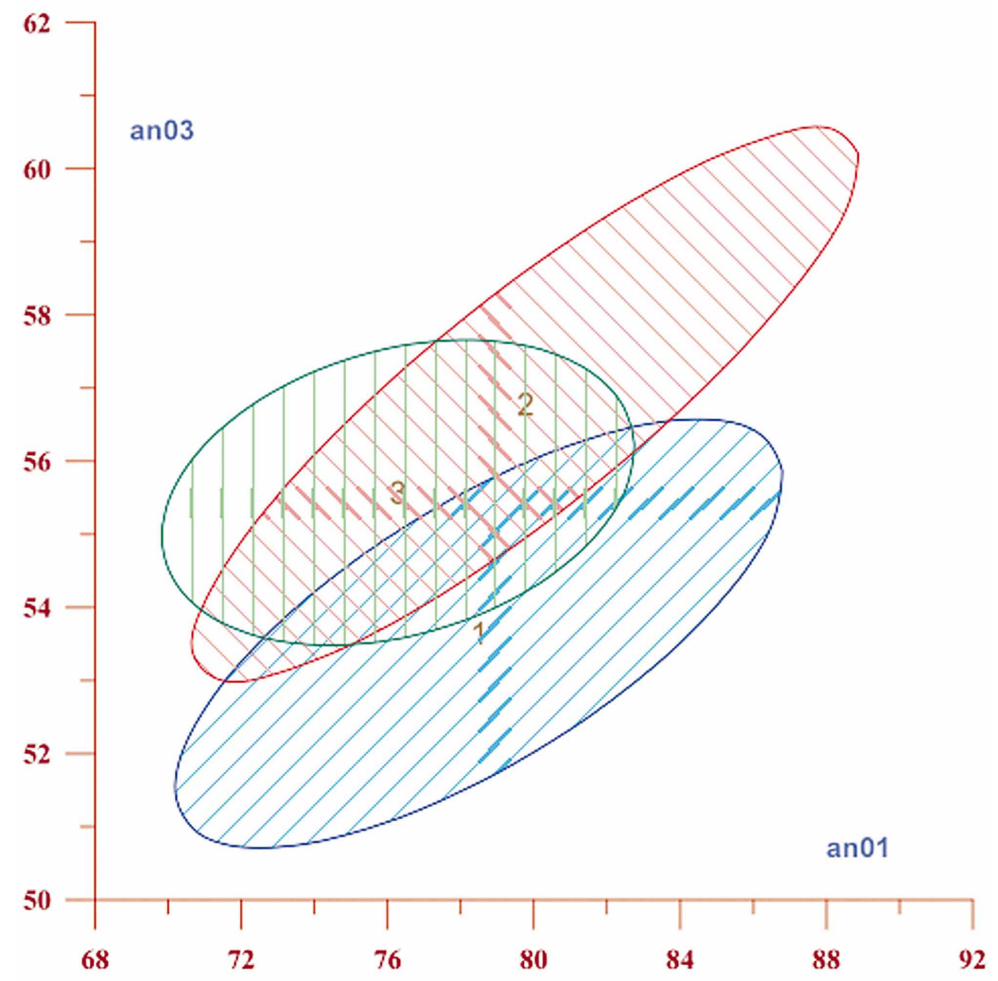

Fig. 3. Ellipses (confidence interval) of basic turn of subjects by body mass and volume of the thigh. Legend: "poor" (1), "moderate" (2) "goods" (3), body mass (an01), volume of the thigh (an03). 
In Figure 4, $\mathrm{x}$-axis (horizontal axis) is the skinfolds of the abdomen (an08), and the ordinate (vertical axis) is the thigh volume (an03). It is noted that in relation to the abdominal skinfold subsample "good" (3) has the lowest value of anthropometric characteristics, and the highest value is for the sub-sample "moderate" (2). In relation to the thigh volume, subsample "weak" (1) has the lowest value of anthropometric characteristics, and the highest value is for the sub-sample "moderate" (2).

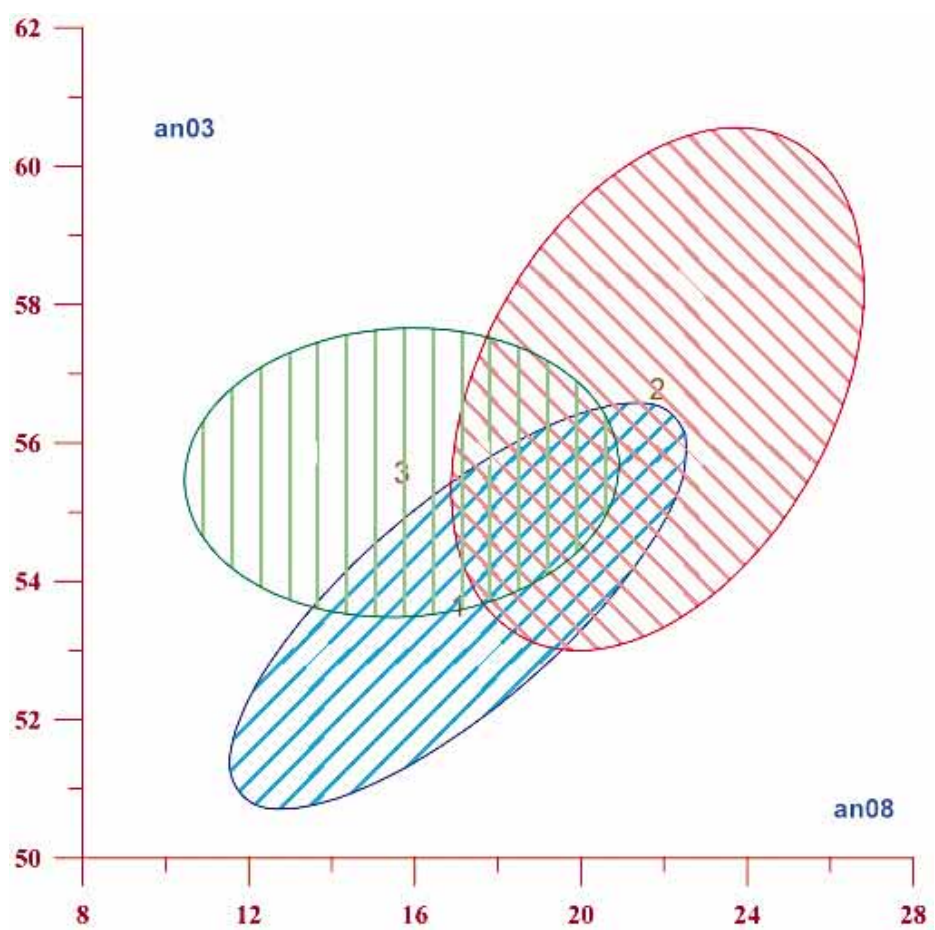

Fig. 4. Ellipses (confidence interval) for basic turn of subjects in skinfolds of the abdomen and thigh volume. Legend: "poor" (1), "moderate" (2) "goods" (3), skinfolds of the abdomen (an08), thigh volume (an03).

\section{CONCLUSION}

A sample of 30 subjects was analyzed and divided into three subgroups, based on the score obtained by the performance techniques of basic turn.

In accordance with pre-determined objectives of the research, the methodological approach of this study analyzed the difference in the technique of basic turn between the respondents in relation to anthropometric characteristics.

Based on the results, their interpretation can give us the following conclusions:

For anthropometric characteristics of respondents, by using discriminant analysis (DISKRA, 0.000), the results indicate that the technique of basic turn shows difference between the three sub-samples with a coefficient of discrimination: body mass (0.662), abdominal skinfold (0.584), the volume of the thigh (.581), forearm skin fold (0.527), pelvic width $(0.447)$, body height $(0.366)$, lower leg length $(0.218)$, knee diameter (0.176), shoulder width (0.117), skinfold (0.110), arm length (0.064), chest circumference (0.022).

As the differences are established and boundaries clearly defined the characteristics and homogeneity of each subsample are determined.

Based on the anthropometric characteristics of the respondents it can be concluded that:

Subsample defined as "poor" has a less pronounced body height, diameter of the knee and thigh girth. Moderately expressed are body mass, abdominal skinfold, upper arm skin fold, shoulder width, skinfold, arm length and circumference of the chest.

More pronounced are length of the lower leg and pelvic width. Homogeneity of the subsamples 'weak', 92.86\%.

Subsample defined as "moderate" has less pronounced skin fold, arm, lower leg length and arm length. Moderate pronounced are the width of the pelvis and knee diameter.

More expressed is body mass, abdominal skinfold, thigh circumference, body height, shoulder width, skinfold and circumference of the chest. Homogeneity of the subsamples 'moderate' is $66.67 \%$.

Subsample defined as "goods" has less pronounced body mass, abdominal skinfold, pelvic width, shoulder width, skinfold and circumference of the chest. Moderate expressed are body high, shoulder width, abdominal skinfold, body mass, arm length and width of the pelvis.More expressed are thigh girth, body height and lower leg length. Homogeneity of the subsamples "good" is $85.71 \%$. 
HADZIC, R.; BJELICA, D.; GEORGIEV, G.; VUJOVIC, D. \& POPOVIC, S. Características antropométricas de sujetos en la predicción de técnicas de rendimiento en el giro básico de esquí alpino. Int. J. Morphol., 32(1):232-240, 2014.

RESUMEN: El objetivo de este estudio fue determinar la diferencia en la técnica de rendimiento de un giro básico de esquí alpino en relación a las características antropométricas de los sujetos. En una muestra de 30 estudiantes de sexo masculino con una edad promedio de 22 años, se realizó una prueba motor circunstancial, al igual que la medición de 12 parámetros antropométricos. La técnica de esquí alpino fue evaluada a través de giros primarios. Esta técnica está presente en la forma básica del esquí alpino. En base a estos resultados, podemos concluir que se establecen las diferencias y los límites se definen claramente en el nivel de adopción de las técnicas básicas de giro entre las submuestras en relación a las características antropométricas.

PALABRAS CLAVE: Esquí alpino; Giro básico; Características antropométricas.

\section{REFERENCES}

Cigovski, V.; Matkovic, B. \& Matkovic, B. Is it more effective way of teaching alpine skiing without the use of pulmonary ski technique? Sportlogija, 2:41-8, 2010.

Hadzic, R. Technique and methodology of skiing (in Montenegrin). Rozaje, Copyright Edition, 2008.

Hadzic, R.; Bjelica, D.; Vujovic, D. \& Popovic, S. Influence of motor abilities on quality of performing technical elements in alpine skiing. Tech. Technol. Educ. Manag.-TTEM, 7(4):1641$5,2012$.

Hirano,Y. \& Tada, N. Numerical simulation of a turning alpine ski during recreational skiing. Med. Sci. Sports Exerc., 28(9):1209$13,2005$.

Hörterer, H. Carving skiing. Orthopade, 34(5):426-32, 2005.

Joksimovic, S.; Joksimovic, A. \& Hadzic, R. The load of musculature in ski carving and relaxation technique. Fizic ${ }^{2} \mathrm{ka}$ Kultura, 2:276-7, 2009.

Kuna, D.; Franjko, I. \& Males, B. The effect of some motor skills in the implementation of the giant slalom of ski instructor. Contemporary Kinesiology, 2008. pp.147-52.

Lesnik, B.; Murovec, S. \& Gaspersic, B. Opredelitev oblik drs`enja in smuc anja. In: Gucek, A. \& Videmsek, D. Smucanje danes. Ljubljana, ZUTS, 2002. pp.28-90.

Misigoj-Durakovic, M. Kinantropologija. Zagreb, Kinezioloski fakultet Sveucilista u Zagrebu, 2008.

Murovec, S. Na kanto!: UPS- ucenje s podaljsevanjem smuci. Kranj, Format Kranj, 2006.
Correspondence to:

Rasid Hadzic

Faculty for Sport and Physical Education

University of Montenegro

Narodne omladine bb, 81400 Niksic

MONTENEGRO

Phone: 00382 (40) 235207

Fax: 00382 (40) 235200

Email: rera@t-com.me

Received: 24-09-2013

Accepted: 19-11-2013 